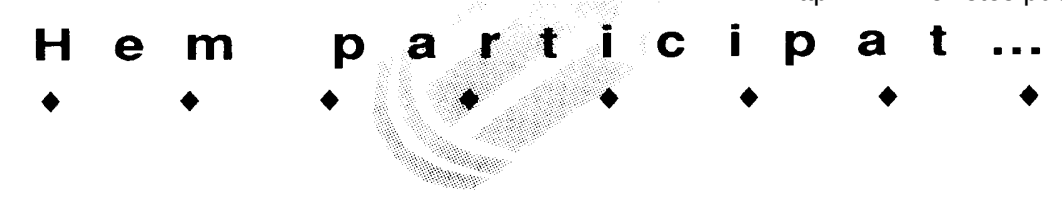

\section{SIMPOSI INTERNACIONAL DE FILOSOFIA DE L'ESPORT}

L'Escola de Mestres va participar en el Simposi Internacionalde Filosofia de l'Esport, celebrat a Barcelona durant la primera setmana de març. Un grup de 22 alumnes de primer curs hi van assistir, dins les activitats programades a l'assignatura de Teoria i Història de l'Educació.

En aquesta trobada varen ser analitzades detalladament les influències que genera l'esport en la personalització de l'ésser humà, i la correlació existent entre esport i societat, fent especial èmfasi en la necessitat de modificar alguns dels processos educatius que genera, com la competitivitat excessiva, la professionalització de l'activitat esportiva d'élite...

Els alumnes i professors assistents varen participar activament en les sessions de treball, presentant les seves comunicacions. Dins els actes programats, visitaren les instal.lacions dels Jocs Olímpics i la seu de l'INEF.

\section{SEMINARI INTERNACIONAL: EDUCACIÓ I DEMOCRÀCIA}

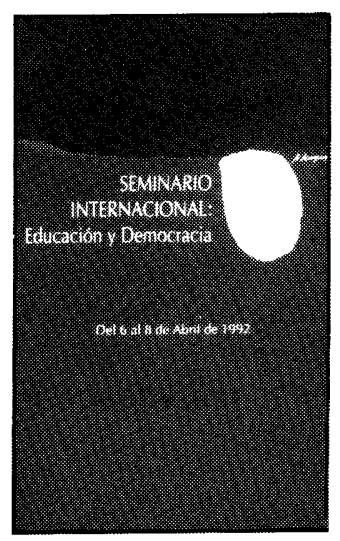

El mes d'abril 25 alumnes de primer curs varen assistir alSeminario Internacional Educación y Democracia, celebrat a Múrcia, organitzat per la seva Universitat. Els professors de la nostra Escola, Ignasi Brunet i Luis F. Valero, varen presentar dues comunicacions sobre el paper que juga l'educació en el desenvolupament del procés democràtic i els aspectes que Rousseau i la seva concepció educativa han aportat a la configuració del marc de l'educació democràtica. El Seminari, que va comptar amb la participació de coneguts filòsofs educatius europeus, com els professors Camps, Appel i Carr, entre altres, va discutir àmpliament la correlació entre educació i democràcia, així com la seva implicació amb la realitat.

Luis F. Valero

Teoria i Història de l'Educació

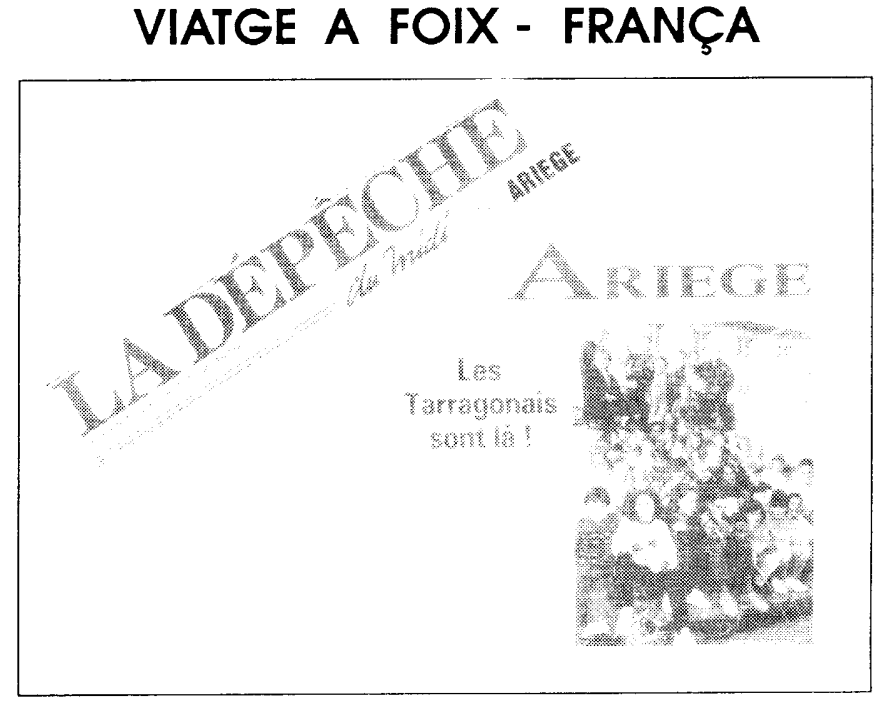

Aquest viatge és una part important de la programació de l'experiència d'ensenyament precoç d'una llengua estrangera al Cicle Mitjà d'EGB, que realitzem per segona vegada a l'Escola de Mestres de Tarragona. Iniciada a l'octubre de 1990, durarà fins al maig de 1993 amb els mateixos nens i nenes del Col. legi de Pràctiques. No es tracta d'una interferència en les activitats extrascolars d'un col.legi públic, sinó d'una activitat programada com a complement de les classes d'idioma que es realitzen, els dimarts i els dijous, durant dues hores setmanals.

Perquè el viatge sigui apreciat com una rica experiència personal per cada nen, ha estat necessària una preparació lingüistica i social molt important.

Primerament, la metodologia: basada en la pedagogia activa-cooperativa de Freinet, utilitzem la tècnica de l'expressió lliure que incita el nen a manifestar la seva personalitat mitjançant l'expressió verbal en llengua estrangera. La motivació i la responsabilitat sorgeixen del mateix nen, que pren consciència del seu aprenentatge.

Des del primer any, els nens ja coneixien la possibilitat d'un viatge a França, però va ser a l' inici del segon curs, el 1991, quan vàrem començar a perfilar-lo amb mapes, xerrades, fulls turístics, visites de francesos a classe, etc., amb la qual cosa França deixava de seruna abstracció.

El projecte de treball del curs és el tema global del viatge a Foix, que ocupa totes les activitats de l'any: des de jocs de rolde situacions simulades (botigues, trobades, càlcul del canvi de moneda, fer la maleta, etc.) a cartes dirigides als nens de l'escola annexa, que ens esperaven molt il.lusionats. El fet que el mestre d'aquest grup, J.Louis Ortiz, treballi amb pedagogia activa ens va ajudar moltíssim. 


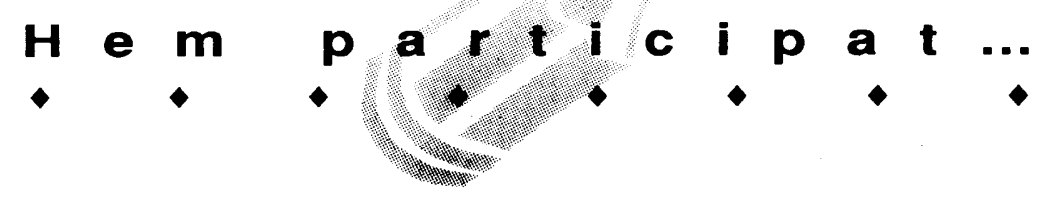

L'aspecte interdisciplinari es manifestà en la col.laboració d'uns professors de la nostra Escola de Mestres, que ens van fer unes xerrades sobre la formació geològica dels Pirineus i la història dels càtars, ja que haviem previst unes excursions a una cova prehistòrica i a un castell càtar. La preparació material del viatge és complexa, perquè tot es fa a classe: permisos al director del Col.legi de Pràctiques, als pares dels nens, autoritzacions, reunions, cartes a l'escola de Foix i altres centres, al director, als nens francesos, cartes a la residència, bitllets de tren, assegurances, excursions previstes, pressupost de despeses, etc.

En principi, són els estudiants de magisteri els qui aprenen a organitzar i realitzar un viatge a l' estranger, a més de fer de "padrins" dels nens.

Aquest és el programa general

\section{Voyage à Foix}

Du lundi 9 au dimanche 15 mars 1992

\section{Lundi 9}

- 6h. Départ de Tarragona, arrivée à Foix à 15h.30.

- Visite de la ville et du Château.

Mardi 10

- Dans les classes.

- Dans les classes. Visite aux Francas.

Mercredi 11

- Avec les Francas à la neige: Plateau de Beille.

Jeudi 12

- Excursion à Vals, Mirepoix, Montségur avec les enfants de l'Ecole Annexe.

Vendredi 13

- Visite au marché de Foix.

- Réunion de travail au Centre de Documentation Pédagogique encollaboration avecle CRDP de Toulouse.

- Les enfants dans les classes.

Samedi 14

- Visite à l'ecole de Cadirac: Radio CADI des enfants.

- Visite à la grotte de Niaux. Temps libre.

Dimanche 15

- 6h. Départ de Foix, arrivée à Tarragona vers 15 h.

\section{Hébergement : Foyer Léo Lagrange.}

També es programaren visites dels estudiants a altres escoles i al Centre Departamental de Documentació Pedagògica, on la directora Mme. Galy ens organitzà una reunió de treball amb professors de Toulouse, per presentar els últims avenços en informàtica a l'escola.

Aquest any han participat en el viatge el director de l'Escola de Mestres, Sr. Gimeno iel professor de geologia,
Sr. Antón, perconcretar l'oferta de material ila col.laboració entre centres pedagògics de l'Ariège i l'Escola de Tarragona. Per aquest motiu ens va rebre el president del Consell de l'Ariège (un equivalent al President de la Diputació) i es va mostrar molt satisfet per l'inici de treballs conjunts $i$ de futurs intercanvis, tant d'experiències pedagògiques i material com de professors, mestres, estudiants i alumnes. Pròximament, Mme. Galy vindrà a la nostra Escola a explicar-nos el detall d'aquesta col.laboració.

La estada a Foix és una experiència molt bonica per als nostres nens. Van a classe i d'excursió amb els nens francesos, i cada dia són convidats a sopar per les famílies i tornen a la residència contents del que han vist i menjat a les cases dels amics. Han hagut d'espavilar-se sols per comprendre i fer-se comprendre i això és una experiència única i emocionant.

Vàrem fer tres excursions, al Plateau de Beille, a més de $2.000 \mathrm{~m}$., perfer esqui de fons, i a la cova de Niaux per admirar, durant més d'una hora de camí en la profunditat de la cova, les meravelloses pintures rupestres. A l'excursió del castell de Montségur varen recordar, amb el mestre i els nens de l'Escola Annexa, la història dels càtars cremats. La visita al castell de Foix els va agradar molt per l'aspecte medieval i el seu museu, així com el mercat d'animals, amb truites vives, oques, fetges enormes perferfoie-gras, pa de pagès, formatges i altres productes del Pirineu i de l'Ariège.

Finalment, la visita a l'escola de Cadirac, un barri de Foix, on els dissabtes al matí, una emissora de ràdio, completament manipulada per nens de sis a dotze anys, emet un programa amb comentaris actuals sobre assumptes escolars, ciutadans i polítics. Els nostres nens també van participar en una entrevista radiada.

Amb la tornada a Tarragona, encara no s'acaba el viatge. S'han d'escriure cartes als amics i s'ha de fer un àlbum amb un resum de cada dia amb les fotografies $i$ records que hem portat. Aquest àlbum és col.lectiu i tots hiparticipen, en la confecció i en les sessions informatives als pares i a altres grups de nens del seu col.legi. A més, els nens francesos que ens van rebre tan cordialment han promès venir aviat a Tarragona, i els esperem.

L'any que ve és el darrer curs d'aquesta experiència. La motivació dels nens és gran. S'adonen de la utilitat pràctica i immediata de l'ús de la llengua estrangera i de les seves limitacions. Per això demanen més hores de classe de francès per treballar de ferm, i sobretot ... repetir el viatge.

Lluïsa Vallès Ferrer Didàctica de la Llengua i la Literatura 